\title{
Bilateral Scalp Necrosis: A Rare Manifestation of Giant Cell Arteritis
}

\author{
Gemy Maria George, $M D^{7}$ and Jacob Ninan, $M D^{2}$ \\ 'John H Stroger Jr. Hospital of Cook County, Chicago, IL, USA; ${ }^{2}$ Mayo Clinic Health Systems Franciscan Healthcare, La Crosse, WI, USA.
}

KEY WORDS: giant cell arteritis; scalp necrosis; temporal arteritis.

$\mathrm{J}$ Gen Intern Med 31(11): 1395

DOI: $10.1007 / \mathrm{s} 11606-016-3707-1$

(c) Society of General Internal Medicine 2016

\begin{abstract}
A n 80-year-old woman presented with 3 weeks of fever, chills and bifrontal scalp pain with necrotic skin changes. She had difficulty swallowing and masticatory claudication before the skin changes occurred. Clinical examination revealed necrotic areas in the frontal region spreading to bilateral parietal and temporal regions of the scalp (Figs. 1 and 2). Her erythrocyte sedimentation rate (ESR) and C-reactive protein (CRP) were $48 \mathrm{~mm} /$ hour and $3.61 \mathrm{mg} / \mathrm{dl}$, respectively. Scalp biopsy revealed granulomatous vasculitis involving deeper tissues. Temporal artery biopsy confirmed giant cell arteritis with extensive inflammatory cell infiltration and fragmentation of internal elastic lamina. The patient had marked improvement of skin lesions and resolution of her systemic symptoms with a few months of oral steroid therapy.
\end{abstract}

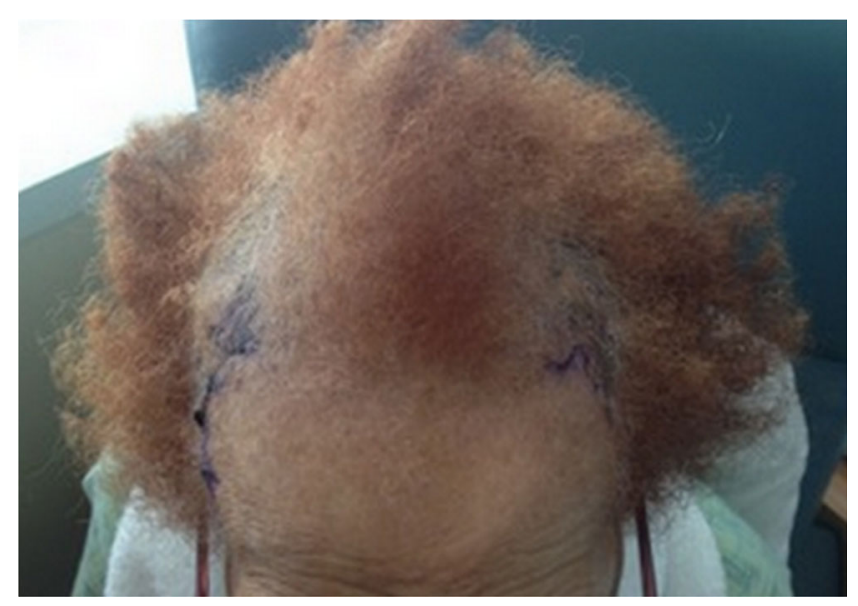

Figure 1. Bilateral view of the scalp showing necrotic, ulcerative lesions in the parieto-temporal region.

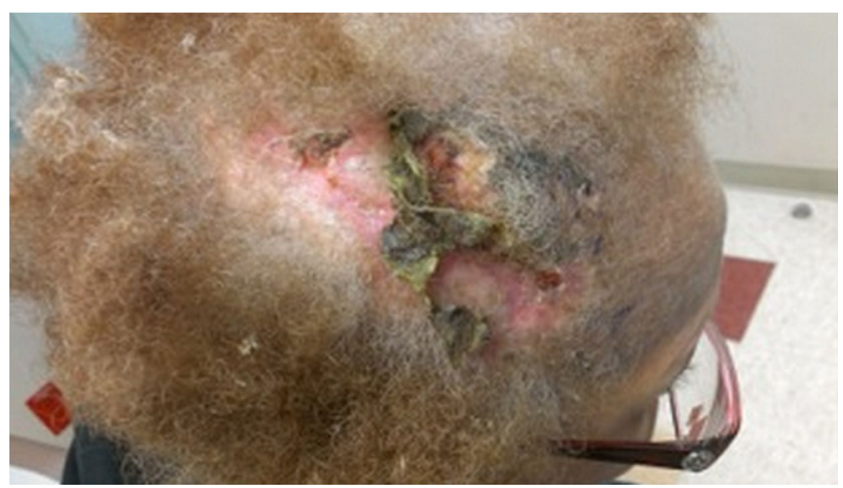

Figure 2. Right side of scalp.

Common symptoms of Giant Cell Arteritis (GCA) include headache, jaw claudication, visual changes, fever and symptoms of polymyalgia rheumatica. Erythrocyte sedimentation rate is typically greater than $50 \mathrm{~mm} /$ hour. Cooke et al. reported the first case of scalp necrosis in GCA in 1946. ${ }^{1}$ Necrotic changes are thought to be secondary to tissue ischemia from occlusive inflammation of the artery. In most cases, lesions heal completely with steroid therapy. Scalp necrosis is a well-documented but very rarely encountered manifestation of GCA, which requires prompt recognition and initiation of steroid therapy.

Corresponding Author: Gemy Maria George, MD; John H Stroger Jr. Hospital of Cook County, Chicago, IL, USA (e-mail: gemy.maria@gmail.com).

\section{Compliance with Ethical Standards:}

Conflicts of Interest: The authors declare that they do not have a conflict of interest.

\section{REFERENCE}

Revised March 28, 2016

Accepted April 4, 2016

Published online April 25, 2016
1. Cooke WT, Cloake PCP, Govan ADT, Colbeck JC. Temporal arteritis: a generalized vascular disease. Q J Med. 1946;15:47-75. 